\title{
PERFIL SOROLÓGICO, ISOLAMENTO BACTERIANO E VALORES HEMATOLÓGICOS E URINÁRIOS EM CÃES NATURALMENTE INFECTADOS COM Brucella canis
}

\author{
SEROLOGY, BACTERIAL ISOLATION, HEMATOLOGICAL AND URINARY \\ VALUES IN DOGS NATURALLY INFECTED WITH Brucella canis
}

\author{
Jane Megid $^{1}$ Carla Cristina Guimarães de Moraes $^{2}$ \\ Gilberto Marcos Junior ${ }^{2}$ Jorge Vitor Bacila Agottani ${ }^{3}$
}

RESUMO

Descrevem-se os parâmetros hematológicos, urinários, perfil sorológico de aglutininas antibrucélicas e resultados de isolamento bacteriano de swab vaginal, líquido prostático e hemocultura de 12 cães naturalmente infectados por Brucella canis. Observaram-se flutuação dos resultados sorológicos, ausência de isolamento de B. canis nos diversos materiais colhidos e valores hematológicos e urinários predominantemente normais. Discute-se o diagnóstico de brucelose canina em nível individual.

Palavras chave: brucelose, cães.

\section{SUMMARY}

This work describes the serology, bacterial isolation of vaginal swabs and hemoculture and hematological and urinary values of twelve dogs naturally infected wilth Brucella canis. Flutuation of positive results in the serology, absence of isolation of $\boldsymbol{B}$. canis in the hemoculture and vaginal swabs, and normality of haematological and urinary parameters were observed in the infected animals.

Key words: brucellosis, dog.

\section{INTRODUÇÃO}

A brucelose canina causada pela B.canis é uma enfermidade infecto-contagiosa, de caráter zoonótico, caracterizada, principalmente, por abortos e esterilidade nas fêmeas e orquite e epididimite nos machos. Foi descrita, inicialmente, nos Estados Unidos em 1966 e, a partir daí identificada em todo o mundo (BERTHELOT \& GARIN-BASTUJI, 1993), inclusive no Brasil (SCHLEMPER \& VAZ, 1990; GERMANO et al., 1987; NETO et al., 1992; VARGAS et al., 1996). Apesar do seu caráter sistêmico, os valores sangüíneos, bioquímicos e urinários normalmente não apresentam alterações (JOHNSON \& WALKER, 1992), impossibilitando a utilização desses dados quando da suspeita clínica. Dessa forma, o diagnóstico da enfermidade baseia-se no isolamento do agente através de hemocultura e cultivo de material abortado, secreções vaginais e uterinas, urina, sêmen e líquido prostático.Também pode ser realizado através da sorologia dos animais, sendo esse método o mais utilizado em função da dificuldade de realização do isolamento bacteriano (JOHNSON \& WALKER,1992). Pretendeu-se, no presente trabalho, avaliar os resultados obtidos em exames bacteriológicos, valores hematológicos e urinários e perfil sorológico apresentados por cães naturalmente infectados.

\section{MATERIAL E MÉTODOS}

Foram acompanhados, através de sorologia, hemocultura e cultivo de material genital ou urina, 12 cães da raça poodle ( 02 machos e 10 fêmeas), com idade variável entre 6 meses e 7 anos, natu-

\footnotetext{
${ }^{1}$ Professor Assistente, Doutor do Departamento de Higiene Veterinária e Saúde Pública, Faculdade de Medicina Veterinária e Zootecnia(FMVZ), UNESP, Botucatu, SP, CP 560, 18618-000. Botucatu-SP. Email- megid@ laser.com.br. Autor para correspondência.

${ }^{2}$ Pós-graduandos do Departamento de Higiene Veterinária e Saúde Pública, FMVZ, UNESP, Botucatu.

${ }^{3}$ Médico Veterinário do Instituto Tecnológico do Paraná, TECPAR. 
ralmente infectados com Brucella canis, pertencentes a um mesmo canil. Este estabelecimento caracterizava-se por vendas constantes de coberturas de seus machos e cobertura de suas fêmeas por diferentes machos, aliado à ausência de medidas profiláticas direcionadas contra brucelose. Das 10 fêmeas sorologicamente positivas, 7 tinham histórico de repetição de abortos, partos prematuros, nascimento de filhotes fracos e morte perinatal. Os machos apresentavam, como histórico, ocorrência de abortos decorrente de suas coberturas e positividade sorológica em fêmeas por eles cobertos. Os animais foram mantidos em isolamento, no setor de Enfermidades Infecciosas dos Animais-FMVZ-UNESP-Botucatu e submetidos a colheitas de sangue periódicas, através de punção jugular, por um período de 9 meses. Os soros obtidos foram submetidos à prova de imunodifusão em ágar-gel, utilizando como antígeno $\boldsymbol{B}$. ovis , produzido pelo Instituto de Tecnologia do Paraná TECPAR, de acordo com a metodologia preconizada pelo laboratório produtor. O teste foi realizado utilizando-se dois soros reagentes em lados opostos da roseta e avaliando-se as reações de identidade através da confluência de linhas dos soros testados frente aos soros positivos. A leitura foi realizada em períodos de $24 \mathrm{~h}, 48 \mathrm{~h}$ e $72 \mathrm{~h}$.

Paralelamente, os soros obtidos foram tratados com 2-mercaptoetanol (2-ME), utilizandose $0,1 \mathrm{ml}$ de soro, adicionado de $0,1 \mathrm{ml}$, de uma solução $0,1 \mathrm{M}$, de 2-ME. Após um período de, no mínimo, 30 minutos, o soro assim tratado foi submetido ao teste de imunodifusão em ágar-gel, para avaliação da especificidade da reação (GEORGE \& CARMICHAEL,1974), avaliando-se de forma semelhante a identidade de reação frente aos soros positivos.

Inicialmente, procedeu-se a colheita de sangue heparinizado para hemograma e hemocultura; não heparinizado para obtenção de soro; e obtenção de urina para urinálise, realizada através de cistocentese das fêmeas e sonda vesical dos machos. Posteriormente, foram realizadas outras 7 colheitas, com intervalo de 3 dias cada, de sangue heparinizado para hemocultura, material vaginal das fêmeas, obtido através de swabs estéreis, e urina ou líquido prostático ou espermático dos machos, colhido por estimulação manual. Após o tratamento, realizou-se em todas as fêmeas, ovariohisterectomia . O material obtido, em todos os momentos, incluindo o útero e ovário obtido após a ovariohisterectomia, foi semeado em ágar-sangue, ágar-brucella adicionado de 5\% de sangue e ágar Mac Conkey, mantidos em estufa a $37^{\circ} \mathrm{C}$, durante 7 dias, e submetidos à identificação bacteriana através de características tintoriais, morfológicas e bioquímicas (CARTER \&
CHENGAPPA, 1988). Para a hemocultura, adicionalmente, o sangue foi semeado em BHI, congelado uma noite a $-20^{\circ} \mathrm{C}$, descongelado e mantido em estufa a $37^{\circ} \mathrm{C}$ por 7 dias (BERTHELOT \& GARINBASTUJI, 1993). Os valores hematológicos e urinários foram obtidos uma única vez, respectivamente, através de colheita sangüínea por punção jugular, utilizando heparina como anticoagulante e urinária através de cistocentese, sendo encaminhados, imediatamente após, para análise no Laboratório de Análises Clínicas da FMVZ-UNESP, Botucatu.

\section{RESULTADOS E DISCUSSÃO}

Durante todo o período do experimento, os animais foram observados diariamente, não se verificando quaisquer alterações clínicas evidentes.

Verificou-se, nos materiais procedentes de swab vaginal, variação de flora com predominância de Staphylococcus $s p$. coagulase positivo, seguida por Streptococcus $s p$ e Corynebacterium $s p$. Observou-se o isolamento em menor proporção de E.coli e Alcaligenes faecalis (Tabela 1). Os agentes bacterianos isolados da vagina das fêmeas são agentes considerados flora normal. A variação observada pode ser justificada em função do ciclo estral dos animais (BARSANTI \& JOHNSON, 1990).

A hemocultura resultou negativa em todos os períodos avaliados. Não se obteve isolamento de B.canis nos diversos materiais e períodos analisados. O não isolamento de $\boldsymbol{B}$. canis em secreções vaginais, prostáticas, urina e sangue pode ser justificado pela ausência de bacteremia nos animais, o que poderia ser um indicativo de infecção crônica nos animais adultos. Nos animais jovens impúberes a $\boldsymbol{B}$. canis não é isolada freqüentemente de secreções vaginais em função da seletividade do agente pela maturidade sexual (JOHNSON \& WALKER, 1992). Pode ser justificada adicionalmente pela necessidade de utilização de meios de cultura seletivos adicionados de antibióticos para redução de flora contaminante, o que facilitaria o isolamento de $\boldsymbol{B}$. canis (CARMICHAEL, 1990).

Verificou-se na sorologia, em todos os animais, flutuação de resultados positivos e negativos no período de tempo avaliado (Tabela 2). A presença de resultados positivos e negativos nos animais foi verificada neste trabalho e relatada por JOHNSON \& WALKER (1992), sendo justificada pela bacteremia intermitente, levando a desaparecimento ou diminuição de títulos sorológicos, porém com persistência do agente nos tecidos infectados (JOHNSON \& WALKER, 1992; CARMICHAEL, 1976). 
Tabela 1 - Bactérias isoladas a partir de swab vaginal de fêmeas naturalmente infectadas com B. canis, 1997.

\begin{tabular}{|c|c|c|c|c|c|c|c|c|}
\hline Data & $21 / 11$ & $25 / 11$ & $28 / 11$ & $3 / 12$ & $5 / 12$ & $9 / 12$ & $12 / 12$ & $15 / 12$ \\
\hline $01 *$ & ST.+ & ST.+/STr & ST.-/ STr & $\begin{array}{l}\text { ST.+/ Cor/ } \\
\text { E.co }\end{array}$ & $\begin{array}{l}\text { ST.-/ STr/ } \\
\text { Cor. }\end{array}$ & ST.- & ST.- & $\begin{array}{l}\text { ST.-/ STr } \\
\text { Cor }\end{array}$ \\
\hline 02 & ST.+/ Cor & STr/ E.co & ST.-/ Cor & Cor & $\mathrm{STr}$ & ST.+/ ST.- & STr & STr/ ST.- \\
\hline 04 & ST.+ & ST.+ & ST.+ & ST.+/ST.- & ST.- & ST.+ & ST.- & ST.+ \\
\hline 05 & neg & ST.+/ Cor & $\mathrm{STr}$ & ST.-/ E.co & $\mathrm{STr}$ & ST.+ & ST.- & neg \\
\hline 06 & neg & neg & $\begin{array}{c}\text { ST.-/ E.co/ } \\
\text { A.faec }\end{array}$ & ST.-/ STr & ST.+ /ST.- & ST.- & ST.- & ST.+ \\
\hline 08 & ST.+/ Cor. & ST.+/ Cor. & ST.+/STr & ST.-/ STr & ST.-/ STr & $\mathrm{STr}$ & ST.+/STr & STr/ Cor. \\
\hline 09 & neg & ST.+ & ST.+ & ST.-/ Cor & ST.- & ST.+ & ST.+/ STr & $\begin{array}{c}\text { ST.+ /ST.-I } \\
\text { Cor }\end{array}$ \\
\hline 10 & Cor & ST.+/ Cor & ST.+/ ST.- & ST.- & ST.- & ST.+/STr & ST.+ & ST.+/ ST.- \\
\hline 11 & ST.+ & ST.+ & ST.+ & ST.-/ Cor & ST.- & $\begin{array}{l}\text { ST.+/ ST.- } \\
\text { Cor }\end{array}$ & ST.+ & ST.- \\
\hline 12 & ST.+ & ST.+ & ST.+ & ST.- & ST.- & ST.+ & contam & ST.+ \\
\hline
\end{tabular}

* Número do cão

ST.$+=$ Staphylococcus coagulase positivo

Cor = Corynebacterium $s p$

ST -.= Staphylococcus coagulase negativo

$\mathrm{STr}=$ Streptococcus $s p$

E.co = Escherichia coli

A.faec $=$ Alcaligenes faecalis

neg = ausência de crescimento bacteriano

contam $=$ contaminação
A imunodifusão em ágar-gel, mesmo utilizando como antígeno B. ovis, é considerada uma prova mais específica que a prova de soroaglutinação rápida utilizando 2-mercaptoetanol (JOHNSON \& WALKER, 1992), porém ainda sujeita a resultados falso-positivos, devido a reações cruzadas com outros agentes (CARMICHAEL, 1976) como Pseudomonas aeruginosa e Staphylococcus $s p$ (JOHNSON \& WALKER,1992). Isso dificulta o diagnóstico individual, porém o mesmo não ocorre em canis pela presença da enfermidade em vários animais, associado ao histórico dos mesmos(CARMICHAEL, 1976).

Resultados positivos em soros não tratados com 2-ME e negativos, quando tratados com 2-
ME, podem ser observado na tabela 2 e justificados pela redução das aglutininas inespecíficas, em função do tratamento dos soros com 2-mercaptoetanol, com conseqüente diminuição do título sorológico em 2 vezes (CARMICHAEL, 1976). A redução do título, bem como a diluição prévia dos soros, poderia levar à negatividade verificada em alguns casos, em função da prova de imunodifusão em ágar-gel não apresentar alta sensibilidade e sim alta especificidade(JOHNSON \& WALKER, 1992).

Os valores hematológicos apresentados pelos animais situaram-se, em sua maioria, na faixa de normalidade, tendo sido verificados em somente 2 fêmeas uma leve leucocitose e, em 5 animais, monocitose em grau variável (Tabela 3), alterações

Tabela 2 - Resultados da prova de imunodifusão em ágar-gel, em soros de cães naturalmente infectados com B. canis, submetidos ou não ao tratamento com 2-ME (sem 2-MElcom 2-ME),1997.

\begin{tabular}{|c|c|c|c|c|c|c|c|c|c|c|c|c|c|c|c|c|c|c|c|c|}
\hline & $19 /$ & $25 /$ & $5 / 12$ & $12 /$ & 221 & $13 / 1$ & $22 / 4$ & $6 / 5$ & $16 / 5$ & $\begin{array}{l}23 / \\
5 * *\end{array}$ & $28 / 5$ & $5 / 6$ & $11 / 6$ & $18 / 6$ & $4 / 7$ & $14 / 8$ & $30 / 9$ & $23 /$ & $17 /$ & $13 /$ \\
\hline & $8^{* 1}$ & $11^{*}$ & $*$ & $12^{*}$ & $12^{*}$ & $* *$ & $* *$ & $* *$ & *** & $5^{* *}$ & $* *$ & ** & $* *$ & $* *$ & $* *$ & *** & $* *$ & $10^{* *}$ & $11^{* * *}$ & $\begin{array}{l}12 * \\
*\end{array}$ \\
\hline 01 & $+1+$ & $+1+$ & -- & $+H_{+}$ & $+l+$ & $+1+$ ? & $+/-$ & $+/-$ & $+/-$ & $\mathrm{f}+/-$ & $-/$ & $-/$ & $\mathrm{f}+/-$ & $-/-$ & $-/-$ & $-/$ & $-/$ & $-/$ & $-/$ & $\mathrm{nt}$ \\
\hline 02 & $-1-$ & $-1-$ & $+1-$ & $+1+$ & $+1-?$ & $+1+$ ? & $+/-$ & $+/-$ & $+/-$ & $\mathrm{f}+/-$ & $\mathrm{f}+/-$ & $-/-$ & $+/-$ & $+/+$ & $-/-$ & -1 & $-/$ & $-/$ & $-/$ & $\mathrm{nt}$ \\
\hline 03 * & $-1-$ & $-1-$ & $-1-$ & $-1-$ & $+1+$ & $+1+$ & $+/-$ & $\mathrm{f}+/-$ & $-/$ & $-/-$ & $-/$ & $-/-$ & $\mathrm{f}+$ & $-/$ & $-/-$ & $-/$ & $-/$ & $-/$ & $-/$ & $\mathrm{nt}$ \\
\hline 04 & $+1+$ & $+1+$ & $\mathrm{nt}$ & $+1+$ & $+1+$ & $+1+$ & $+/+$ & $\mathrm{f}+/-$ & $+/-$ & $+/-$ & $-/-$ & $-/-$ & $+/-$ & $-/$ & $-/-$ & $-/$ & $-/$ & $-/-$ & $-/-$ & $\mathrm{nt}$ \\
\hline 05 & $+1-$ & $+1-$ & $+1-$ & $+1+$ & $+1-$ & $+1-$ & $+/-$ & $+/-$ & $+/-$ & $\mathrm{f}+/-$ & -1 & $-/-$ & $+/-$ & $-/$ & $+/+$ & -1 & $+/+$ & $-/-$ & $-/-$ & $\mathrm{nt}$ \\
\hline 06 & $+1-$ & $+1-$ & $+1-$ & $+1+$ & $+1+$ & $+1-$ & $+/-$ & $+/$ & $+/-$ & $\mathrm{f}+/-$ & -1 & $+/+$ & $+/-$ & -1 & -1 & -1 & $-1-$ & $-/$ & $-/$ & $\mathrm{nt}$ \\
\hline 07 • & $+1+$ & $+1+$ & $+1+$ & $+1+$ & $+1+$ & $+1+$ & $+/+$ & $+/+$ & $+/$ & $+/$ & $-/$ & $-/-$ & $+/+$ & $-/$ & $-/$ & $-/$ & $-/$ & $-/$ & $-/$ & $\mathrm{nt}$ \\
\hline 08 & $+1+$ & $+1+$ & $+1+$ & $+1+$ & $+1+$ & $+1+$ & $+/+$ & $+/$ & $+/$ & $+/-$ & $-1-$ & $-/-$ & $+/+$ & $-/-$ & $-/$ & $-/$ & $-/$ & $-/$ & $-/-$ & $\mathrm{nt}$ \\
\hline 09 & $+1+$ & $+1+$ & $\mathrm{nt}$ & $+1+$ & $+1+$ & $+1+$ & $\mathrm{f}+/-$ & $+/-$ & $+1-$ & $\mathrm{f}+/-$ & -1 & $-/-$ & $+/+$ & $-/$ & $-/$ & -1 & $-/$ & $-/$ & $-/-$ & $\mathrm{nt}$ \\
\hline 10 & $+1+$ & $+1+$ & $+1+$ & $+1+$ & $+1+$ & $+1+$ & $+/-$ & $+/+$ & $+1-$ & $\mathrm{f}+/-$ & -1 & $-/-$ & $+/+$ & $-/$ & $-/$ & -1 & $-/$ & $-1-$ & $-/-$ & $\mathrm{nt}$ \\
\hline 11 & $+1+$ & $+1+$ & $+1+$ & $+1+$ & $+1+$ & $+1+$ & $+/+$ & $+/+$ & $+/+$ & $+/ t$ & -1 & $-/-$ & $+/-$ & $-/$ & $-/$ & -1 & $-/$ & $-/$ & $-/-$ & $\mathrm{nt}$ \\
\hline 12 & $+1+$ & $+1+$ & $\mathrm{nt}$ & $+1+$ & $+1+$ & $+1+$ & $+/+$ & $+/+$ & $+/+$ & $+/+$ & $-/$ & $-1-$ & $+/$ & $-/$ & $-1-$ & - & $+/+$ & $+/+$ & $+/+$ & $+/+$ \\
\hline
\end{tabular}

Ciência Rural, v. 30, n. 3, 2000. 
Tabela 3 - Valores hematológicos apresentados por cães naturalmente infectados com B. canis, 1997.

\begin{tabular}{|c|c|c|c|c|c|c|}
\hline Animal & Hemácias & Leucócitos & neutrófilos* & Linfócitos* & eosinófilos* & monócitos* \\
\hline 01 & 6720.000 & 8.137 & 54 & 37 & 03 & 06 \\
\hline 02 & 7010.000 & 7.612 & 49 & 41 & 08 & 02 \\
\hline $03 \%$ & 6050.000 & 12.180 & 62 & 25 & 02 & 06 \\
\hline 04 & 6080.000 & 13.282 & 61 & 33 & 05 & 01 \\
\hline 05 & 6930.000 & 6.775 & 68 & 25 & 05 & 02 \\
\hline 06 & 5780.000 & 17.905 & 67 & 18 & 05 & 10 \\
\hline 07 • & 6110.000 & 10.500 & 38 & 43 & 03 & 15 \\
\hline 08 & 6880.000 & 14.805 & 41 & 47 & 03 & 09 \\
\hline 09 & 6150.000 & 19.425 & 56 & 26 & 05 & 13 \\
\hline 10 & 6780.000 & 10.185 & 68 & 22 & 02 & 08 \\
\hline 11 & 7170.000 & 9.922 & 58 & 19 & 00 & 23 \\
\hline 12 & 7280.000 & 10.552 & 49 & 35 & 01 & 15 \\
\hline
\end{tabular}

* valores expressos em percentual

* machos

que podem ser justificadas pela liberação de corticosteróides endógenos decorrentes de "stress" (MEYER $\boldsymbol{e t}$ al., 1989). De forma semelhante, não se observaram alterações significativas, decorrentes da enfermidade, nos parâmetros urinários apresentados pelos animais (Tabela 4), aspecto concordante com CARMICHAEL \& GREENE (1990). Os parâmetros urinários alterados em alguns animais não apresentaram correlação com a enfermidade.

Tentativas terapêuticas em brucelose canina são questionáveis em função da localização intracelular da bactéria. Em função disso, considerase que animais infectados devem ser eliminados de programas de cobertura e submetidos à antibioticoterapia (CARMICHAEL, 1990), conduta realizada com os animais deste experimento, reduzindo, dessa forma, a possibilidade de transmissão ao ser humano.

O presente trabalho chama a atenção para a flutuação de resultados sorológicos verificados em animais naturalmente infectados com B. Canis, podendo levar a resultados falso-negativos em casos individuais, bem como à dificuldade de isolamento da $\boldsymbol{B}$. canis, nesses animais, tanto em hemocultura como em secreções vaginais.

\section{REFERÊNCIAS BIBLIOGRÁFICAS}

BARSANTI, J.A.,JOHNSON, C.A. Genitourinary infections. In: GREENE, C.E. Infections diseases of the dog and cat. Philadelphia : Saunders, 1990. p.157-158.

BERTHELOT, X., GARIN-BASTUJI, B. Brucelloses canines. Le Point Veterinaire, v.25, p.33-37, 1993.

CARMICHAEL, L.E. Canine brucellosis: an annotated review with selected cautionary comments. Theriogenology, New York, v.6, p.105-116, 1976

CARMICHAEL, L.E. Animal brucellosis. Boca Raton., USA . CRC, 1990. Brucella canis: p.335-350.

Tabela 4 - Parâmetros urinários apresentados por cães naturalmente infectados com B. canis. 1997.

\begin{tabular}{|c|c|c|c|c|c|c|c|c|c|c|c|c|c|}
\hline Animal & $\begin{array}{l}\text { Den- } \\
\text { sidade }\end{array}$ & $\begin{array}{c}\text { Protei- } \\
\text { na }\end{array}$ & glicose & acetona & $\begin{array}{c}\text { sais } \\
\text { biliares }\end{array}$ & $\begin{array}{c}\text { Bilir } \\
\text { rubina }\end{array}$ & $\begin{array}{c}\text { uro } \\
\text { bilinogênio }\end{array}$ & $\mathrm{pH}$ & celulas & hemácias & $\begin{array}{l}\text { Leucó- } \\
\text { citos }\end{array}$ & cilindros & $\begin{array}{c}\text { bactéri } \\
\text { as }\end{array}$ \\
\hline 01 & 1040 & - & - & - & - & - & $\mathrm{n}$ & 7,5 & raras & $2-3$ & $0-7$ & - & + \\
\hline 02 & 1036 & traço & - & - & - & - & $\mathrm{n}$ & 8,0 & - & - & - & - & - \\
\hline 03 * & 1040 & traço & - & - & - & - & $\mathrm{n}$ & 5,0 & raras & raras & Raras & + & + \\
\hline 04 & 1040 & traço & - & - & - & - & $\mathrm{n}$ & 8,0 & - & - & Raras & - & ++ \\
\hline 05 & 1032 & traco & - & - & - & - & $\mathrm{n}$ & 8,0 & - & $0-1$ & $2-3$ & - & ++ \\
\hline 06 & NT & NT & NT & NT & NT & NT & NT & NT & NT & NT & NT & NT & NT \\
\hline 07 . & 1040 & ++ & - & - & - & + & alter. & 8,0 & +ves & $30-35$ & $6-7$ & - & ++ \\
\hline 08 & 1040 & traço & - & - & - & - & $\mathrm{n}$ & 8,0 & - & - & $0-1$ & - & ++ \\
\hline 09 & 1040 & + & - & - & - & - & $\mathrm{n}$ & 9,0 & - & - & - & - & - \\
\hline 10 & 1040 & traço & - & - & - & - & $\mathrm{n}$ & 7,5 & - & $15-20$ & Raros & - & + \\
\hline 11 & NT & NT & NT & NT & NT & NT & NT & NT & NT & NT & NT & NT & NT \\
\hline 12 & 1040 & - & - & - & - & - & $\mathrm{n}$ & 8,0 & - & $25-30$ & Raros & - & - \\
\hline
\end{tabular}

\& machos NT $=$ não testado alter $=$ alterado 
CARMICHAEL, L.E., GREENE, C.E. Canine brucellosis In: GREENE,C.E. Infectious diseases of the dog and cat Philadelphia : Saunders, 1990. p 573-584.

CARTER, R.G., CHENGAPPA, M.M. Fundamentos de bacteriologia e micologia veterinaria. 3.ed. São Paulo : Roca, 1988. 284p.

GEORGE, L.W., CARMICHAEL,L.E. A plate aglutination test for the rapid diagnosis of canine brucellosis. American Journal of Veterinary Research, Chicago, v.35, p.905-909, 1974.

GERMANO, P.M.L., VASCONCELLOS, S.A., ISHIZUKA, M.M. et al. Prevalência da infecção por Brucella canis em cães da cidade de Campinas. Revista da Faculdade de Medicina Veterinária e Zootececnia da Universidade de São Paulo, São Paulo, v.24, p.27-34, 1987.

JOHNSON, C.A., WALKER, R.D. Clinical signs and diagnosis of Brucella canis infection. The Compendium on
Continuing Education for the Practicing Veterinarian. Small Animal, New Jersey, v.14, n.6, p.763-772, 1992.

MEYER, D.J., COLES, E.H., RICH, L.J. Veterinary laboratory medicine interpretation and diagnosis. Philadelphia : Saunders, 1989. 350p.

NETO, M.N., DAURESE, F.W., SANTOS, A.F. $\boldsymbol{e} \boldsymbol{t} \boldsymbol{a l}$. Prevalência de humanos e caninos reatores à Brucella rugosa no município de Pelotas, RS. In: CONGRESSO ESTADUAL DE MEDICINA VETERINÁRIA, 11, 1992, Gramado, RS. Anais... Gramado : Sociedade de Veterinária do RS, 1992. p. 92.

SCHLEMPER, S.R., VAZ, A.K. Inquérito sorológico para Brucella canis na região do planalto catarinense, Brasil. Revista Brasileira de Veterinária, v.12, p.8-12, 1990.

VARGAS, A.C., LAZZARI,A., DUTRA, V. et al. Brucelose canina: relato de caso. Ciência Rural, Santa Maria, v.26, p.306-308, 1996.

Ciência Rural, v. 30, n. 3, 2000. 